\title{
A case of dermoid: Cyst within a cyst
}

\author{
Syed Mahbub Ali ${ }^{1}$, Mohammad Omar Faruq ${ }^{* 2}$, Syed Sakibul Ahsan ${ }^{3}$, Karishma Shamarukh ${ }^{4}$, Amina Sultana ${ }^{5}$
}

A 82 yrs. old lady known to have HTN, DM, Bronchial Asthma and hypothyroidism was admitted to ICU with the complaints of altered mental status for 7 days. She had previous history of recurrent UTI and for this reason she was admitted in hospital for several times. She had no history of fever vomiting convulsion or head trauma. But she had history of constipation.

On examination she was drowsy disoriented, pupils were bilaterally equal and reacting to light. Her all jerks were diminished and planter reflex were flexor bilaterally. Abdominal examination showed an ill-defined movable mass on right flank of abdomen.

A CT scan of brain was done to investigate altered mental status and it showed lacunar infarct. Plain X ray abdomen (flat plate) was done and it showed a round radio opaque shadow on right side.

Eventually a CT abdomen was done and it showed calcified dermoid cyst in the mesentery (Fig 1) which showed another smaller calcified cyst within it (See arrow).

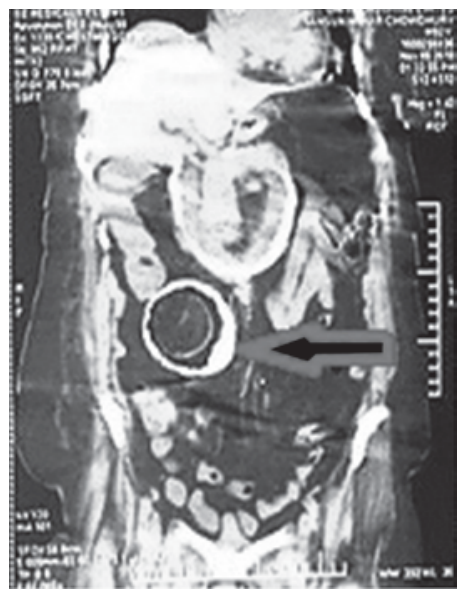

Figure 1

1. Intensivist, General ICU, United Hospital Ltd. Dhaka 1212, Bangladesh.

2. Chief Consultant, GICU and Emergency, United Hospital Ltd.

3. Senior Medical officer, GICU, United Hospital Ltd

4. Intensivist, Covid ICU, United Hospital Ltd.

5. Associate Consultant and in charge Covid ICU, United Hospital Ltd

*Corresponding Author:

Professor Mohammad Omar Faruq MD, FACP, FACEP, FCCM, FCPS

Chief Consultant, GICU and ED

United Hospital, Ltd. Dhaka 1212, Bangladesh

E mail: faruqmo@yahoo.com
USG of whole abdomen shows a well defined cystic area (8.8 $\mathrm{cm}$ in diameter) in the right upper abdomen having eccentric calcification and a well-defined echogenic ball $(4.7 \mathrm{~cm}$ in diameter) with in it suggestive of a dermoid cyst.

\section{Discussion:}

Dermoid cyst is a congenital dysembryogenic lesion. It is a benign, ectopic, and squamous epithelial cyst containing dermal elements, including hair follicles, sebaceous, and sweat glands. CT is usually helpful in the diagnosis of dermoid cyst.

Dermoids and epidermoids are ectoderm-lined inclusion cysts that differ in complexity: Epidermoids have only squamous epithelium; dermoids contain hair, sebaceous and sweat glands, and squamous epithelium ${ }^{1}$.

Although they are slow growing, dermoid and epidermoid inclusion cysts produce pressure changes on surrounding structures that are visible at radiography. Dermoid cyst is also known as benign (mature) teratoma. A teratoma can be suspected when a multiloculated lesion with focal areas of low attenuation and high signal intensity. Radiologically evident lipid may be scattered throughout the mass, rather than forming a single, large collection or fat-fluid level that might suggest a dermoid inclusion cyst.

Dermoids have been described using all imaging modalities, but the specificity for diagnosis of fat and calcification makes CT the modality of choice. One study found CT evidence of fat in $93 \%$ of cases, teeth in $56 \%$ and tufts of hair in $65 \%$, a rokitansky protuberance of dermoid nipple was seen in $81 \%$, a fat fluid level was found in $12 \%$ of ovarian dermoids, and considered diagnostic ${ }^{2}$.

The diagnosis of a cystic mesenteric mass has a wide range of differntials: duplication cyst, cystic mesothelioma, cystic spindle cell tumor and liquefying mesenteric hematoma. Liposarcoma and mesenteric lipodystrophy or calcified lipoma would not be cystic and liposarcoma does not contain fat fluid-levels. Other cystic mass that might contain a fat-fluid level is hydatid cyst, this would generally occur in the liver. Dedifferentiated liposarcoma is most commonly located in the retroperitoneum, which is defined as a neoplasm with a well-differentiated liposarcoma juxtaposed to pleomorphic sarcoma. On the CT and MR images, differentiated liposarcoma is seen as well-defined non-lipomatous masses juxtaposed with fatty tumour ${ }^{3}$.

Dermoids are usually asymptomatic, with most symptoms due to local compression, rupture or infection. Rupture in ovarian dermoids can lead to peritonitis, while in CNS dermoids, it can lead to the fatty, potentially infected material through the sub arachnoid, ventricular, or sub dural compartments ${ }^{4}$. Rarely production of hormones in functional tissue components can 
Bangladesh Crit Care J September 2020; 8 (2): 134-135

occur in a dermoid, leading to complications such as Cushing's disease from over production of ACTH. Malignant transformation of ovarian dermoid cyst is rare with the incidence at approximately $1 \%$ to $2 \%$ of all ovarian neoplasms. Squamous cell carcinoma is most frequent but adenocarcinoma can also occur, they are mostly associated with ovarian dermoid ${ }^{5}$. Biopsy from the cystic lesions is not advisable as it may lead to spillage of malignant cells or infection of the cyst. Also complete excision of the cyst along with the margin of normal tissue followed by careful examination of the specimen is recommended ${ }^{6}$.

Intracranial dermoids commonly occur in cisternal spaces and parasellar location with characteristic imaging appearances. On computed tomography (CT) scan, typically dermoid cysts appear as well defined, low attenuating $(-20$ to -140$)$ due to their lipid content. The sebaceous lipid material within a dermoid cyst has attenuation and signal intensity characteristics that simulate those of fat on both CT scan and magnetic resonance imaging (MRI), thus giving a characteristic hypodense appearance on CT, and are predominantly $\mathrm{T} 1$-weighted (T1-W) hyperintense on $\mathrm{MRI}^{7}$. On MRI sequences, typically, dermoid cyst appears T1 hyperintense (due to cholesterol components) and is heterogeneous on $\mathrm{T} 2-\mathrm{W}$ images. On CT, typically, they are hypodense with attenuation values equal to that of fat density. However, this may not always be the reality.

Mesenteric dermoid cyst are very rare according to literature search. ${ }^{8}$ To our knowledge this is the first reported case of mesenteric dermoid presenting on CT scan as calcified cyst within a calcified cyst.

Removal of dermoid cyst is usually the treatment of choice. Complete surgical removal can be done by laparotomy or laparoscopy, preferably in one piece and without any spillage of cyst contents.

\section{Conclusion:}

Dermoid cyst have a characteristic yet variable in appearance on imaging studies. By being attuned to certain characteristic features, however a radiologist may be able to make a specific diagnosis with confidence, even when the location of the mass is extremely unusual, as seen in this case.

\section{Reference:}

1. Schueltz MJ, Elsheikh TM. Dermoid cyst (mature cystic teratoma) of the cecum. Histologic and cytologic features with review of the literature. Arch Pathol Lab Med 2002;126:97-9.

2. Der. Buy JN, Ghossain MA, Moss AA, et al. Cystic teratoma of the ovary: CT detection . Radiology.1989;171:697-701

3. Ateishi U, Hasegawa T, Beppu Y, Satake M, Moriyama NJ Comput Assist Tomogr. 2003 Sep-Oct; 27(5):799-804.

4. Vermeulen BJ, Widgren S, Gur V, et al. Dermoid cyst of the pancreas. Case Report and review of the literature. Gastroent Clin Biol. 1990;14:1023-1025.

5. Stamp GWH, McConell EM. Malignancy arising in cystic ovarian teratomas. A report of 24 cases. Brit J Obst Gynaecol. 1983;90:671-675.

6. Krivokapic, Dimitrijevic I, Barisic G, Markovic V, Krstic M. Adenosquamous carcinoma arising within a retrorectal tailgut cyst: Report of a case. World J Gastroenterol 2005;11:6225-7.

7. Kim KS, Weinberg PE. Dermoid tumor. Surg Neurol. 1981; 15:375

8. Neeralgi CS, Suroj KR, Lakkama S, Preetham R. Mesenteric teratoma in elderly female: A rare case report. J. Clin.Diagn.Res.2017. 11(1); PD01-PD02 